\title{
Co-existence of isodicentric $\mathrm{Ph}$ chromosomes and the three-way Ph chromosome variant $t(3 ; 9 ; 22)(p 21 ; q 34 ; q 11)$ in a rare case of chronic myeloid leukemia
}

\author{
QIAN LI ${ }^{1}$, XIAO-JI LIN ${ }^{2}$, HUI CHEN ${ }^{1}$, JIAN GONG $^{1}$, ZHEN LI $^{3}$ and XIANG-NAN CHEN ${ }^{1}$ \\ ${ }^{1}$ Department of Clinical Laboratory; ${ }^{2}$ Department of Hematology, The Second Affiliated Hospital and Yuying Children's \\ Hospital of Wenzhou Medical University, Wenzhou, Zhejiang 325000; ${ }^{3}$ Department of Traditional Chinese Medicine, \\ The Third Affiliated Hospital of Guangzhou Medical University, Guangzhou, Guangdong 510000, P.R. China
}

Received July 8, 2017; Accepted December 11, 2017

DOI: $10.3892 / \mathrm{ol} .2018 .7866$

\begin{abstract}
More than $90 \%$ of patients with chronic myeloid leukemia (CML) have the chromosomal translocation $\mathrm{t}(9 ; 22)(\mathrm{q} 34 ; \mathrm{q} 11)$, while $5-8 \%$ of patients have complex variant translocations that have previously been thought not to affect the efficacy of imatinib therapy. The present study reports a patient with CML in B-lymphoid blast crisis who had a rare three-way Philadelphia $(\mathrm{Ph})$ variant $\mathrm{t}(3 ; 9 ; 22)(\mathrm{p} 21 ; \mathrm{q} 34 ; \mathrm{q} 11)$, in addition to isodicentric $\mathrm{Ph}$ chromosomes. The patient was initially treated with imatinib for $>2$ months with a very poor response. When no T315I or F317L mutations in the ABL proto-oncogene 1 region were detected, the patient received dasatinib treatment (140 mg daily) and achieved a complete hematologic response. Following allo-hematopoietic stem cell transplantation, the patient displayed clinical, hematological and cytogenetic remission, with complete molecular response and complete donor chimerism, and stopped taking dasatinib at the last follow-up. The present data suggest that BCR-ABL gene amplification may be associated with imatinib resistance, which can be overcome with dasatinib. The present analysis suggests an alternative therapy strategy for CML involving isodicentric $\mathrm{Ph}$ chromosomes.
\end{abstract}

\section{Introduction}

Chronic myeloid leukemia (CML) is a clonal disorder characterized by the reciprocal translocation between the long arms of chromosomes 9 and 22 [t(9;22)(q34;q11)]. This translocation,

Correspondence to: Dr Xiao-Ji Lin, Department of Hematology, The Second Affiliated Hospital and Yuying Children's Hospital of Wenzhou Medical University, 109 Xueyuan Road, Wenzhou, Zhejiang 325000, P.R. China

E-mail: linxiaoji321@163.com

Key words: chronic myelogenous leukemia, isodicentric $\mathrm{Ph}$ chromosome, t(3,9,22)(p21;q34;q11), imatinib resistance, fluorescence in situ hybridization which is present in $95 \%$ of patients with $\mathrm{CML}$, creates a BCR, RhoGEF and GTPase activating protein (BCR)-ABL proto-oncogene 1 non-receptor tyrosine kinase (ABL) fusion gene that produces an abnormal tyrosine kinase. The imatinib mesylate is commonly used as the first-line oral treatment in patients with CML (1). It blocks the BCR-ABL tyrosine kinase activity and subsequently induces apoptosis, followed by a reduction in the proliferation of BCR-ABL-expressing cells (2). Therefore, the treatment of patients with CML with imatinib significantly increased survival and improved quality of life (3).

A small proportion of patients with CML (5-8\%) present a more complex rearrangement of the Philadelphia $(\mathrm{Ph})$ chromosome $(4,5)$. These complex variant translocations and other mutations may be facilitated by genomic instability triggered by the $\mathrm{t}(9 ; 22)(\mathrm{q} 34 ; \mathrm{q} 11)$ translocation, resulting in accelerated disease progression to blast crisis (6-8). How these events occur in detail remains unknown. The present report describes a patient with CML in B-lymphoid blast crisis who presented with a rare three-way $\mathrm{Ph}$ variant translocation $\mathrm{t}(3 ; 9 ; 22)(\mathrm{p} 21 ; \mathrm{q} 34 ; \mathrm{q} 11)$ in addition to isodicentric $\mathrm{Ph}$ chromosomes.

\section{Materials and methods}

Patient. A 42-year-old Chinese male was admitted to The Second Affiliated Hospital and Yuying Children's Hospital of Wenzhou Medical University (Zhejiang, China) in June 2011 because of neutrophilic granulocytosis and splenomegaly lasting the previous 6 months. Written informed consent from the patient was obtained for publication of this study. Hematological tests revealed a white blood cell count of $69 \times 10^{9} / 1$ (normal range, $4-10 \times 10^{9} / 1$ ), consisting of $67 \%$ neutrophils (normal range, 40-70\%), 5\% lymphocytes (normal range, 20-50\%), 12\% metamyelocytes (normal range, $0 \%$ ), $10 \%$ myelocytes (normal range, $0 \%$ ), $1 \%$ promyelocyte (normal range, $4-10 \times 10^{9} / 1$ ), $1 \%$ eosinophils (normal range, $4-8 \%$ ), $0.5 \%$ basophils (normal range, $0-1 \%$ ) and $3.5 \%$ blasts (normal range, $0 \%$ ); a platelet count of $499 \times 10^{9} / 1$ (normal range, 100-300x10 $/ 1$ ); and a hemoglobin concentration of $92 \mathrm{~g} / 1$ (normal range, 120-160 g/l). Bone marrow examination revealed predominant granulopoiesis, a markedly elevated ratio of granulocytes to erythrocytes, and blasts cells 
accounting for $23 \%$ of all nucleated cells. Flow cytometry revealed high proportions of cells expressing CD10 (23\%), CD19 (97\%), CD13 (96.7\%), CD33 (97.4\%), HLA-DR (98.3\%), and CD34 (85.8\%). Reverse transcription-polymerase chain reaction (RT-PCR) revealed the presence of the p210-type (major) BCR-ABL fusion transcript (Fig. 1).

The patient was diagnosed with CML in B lymphoid blast crisis. He was initially treated with orally administered imatinib (600 mg daily), which was subsequently increased to $800 \mathrm{mg}$. This treatment was deemed ineffective after 65 days, when $13 \%$ of nucleated cells in bone marrow were found to be blast cells. Compared with the GeneBank sequence accession number NM_005157.5, no T315I or F317L mutations were observed in the ABL1 region. The patient was treated with dasatinib (140 mg daily) for 3 months, following which the patient displayed complete hematologic response. Later, the patient received hematopoietic stem cells from an HLA-matched sibling donor, and he underwent myeloablative conditioning. On day 126 following stem cell transplantation, immunosuppressive therapy was withdrew and dasatinib therapy (140 mg daily) was again resumed.

At the last follow-up in September 2016, the patient was alive and displayed clinical, hematological and cytogenetic remission, with complete molecular response and complete donor chimerism (Table I). Dasatinib therapy was halted in May 2014.

Cytogenetic analysis. Unstimulated bone marrow was cultured for 24-48 $\mathrm{h}$ and chromosomes were prepared from these cultures using standard procedures. Chromosomes were analyzed in 20 metaphase cells using G-banding and R-banding, and karyotypes were described according to the International System for Human Cytogenetic Nomenclature (9).

Fluorescence in situ hybridization (FISH). Chromosomes in 500 interphase nuclei cells were analyzed using commercially available FISH probes according to the manufacturers' instructions. The BCR-ABL fusion gene was detected using the probes ES-BCR-ABL and DF-BCR-ABL (GP Gene Company, Beijing, China), the region from the telomere of 22 to 22q11.1 downstream of the BCR breakpoint was detected using the breakpoint probe EWSR1 (22q12) (Anbiping Gene Company, Guangzhou, China), and the region from the centromere of chromosome 22 to 22q11.1 upstream of the BCR breakpoint was detected using the probe CSP22 (22q11) (GP Gene Company). The argininosuccinate synthase (ASS) probe (9q34.1; GP Gene Company) was used to detect the deletion range of ABL gene. The breakpoint probe BCL6 (3q27) (GP Gene Company) was used to detect the presence of $3 q$ end.

$R T$-PCR. Total RNA was extracted immediately from fresh bone marrow cells of the patient. A negative control was used to monitor RNA isolation. Primers and RT-PCR analyses for transcripts of P210 type BCR/ABL, p190-type BCR/ABL and $\beta$-actin were performed as described previously (10).

\section{Results}

Chromosomal analysis at the time of diagnosis revealed 46, XY, idicder(22) t(3;9;22)(p21;q34;q11)[18]/46, XY, t(9;22)(q34;q11) (Figs. 2 and 3). These idic( $\mathrm{Ph}$ ) chromosomes appeared identical
Table I. Evaluation of treatment in the chronic myeloid leukemia patient.

\begin{tabular}{lccc}
\hline & $\begin{array}{c}\text { Hematological } \\
\text { response }\end{array}$ & $\begin{array}{c}\text { Cytogenetic } \\
\text { response }\end{array}$ & $\begin{array}{c}\text { Molecular } \\
\text { response }\end{array}$ \\
\hline Imatinib & $\mathrm{NR}$ & $\mathrm{NR}$ & $\mathrm{NR}$ \\
Dasatinib & $\mathrm{CHR}$ & $\mathrm{PCyR}$ & $<\mathrm{MMR}$ \\
Allo-HSCT & $\mathrm{CHR}$ & $\mathrm{CCyR}$ & $\mathrm{CMR}$ \\
\hline
\end{tabular}

HSCT, hematopoietic stem cell transplantation; NR, no remission; CHR, complete hematological remission; PCyR, partial cytogenetic remission; MMR, major molecular response; CCyR, complete cytogenetic remission; CMR, complete molecular response.

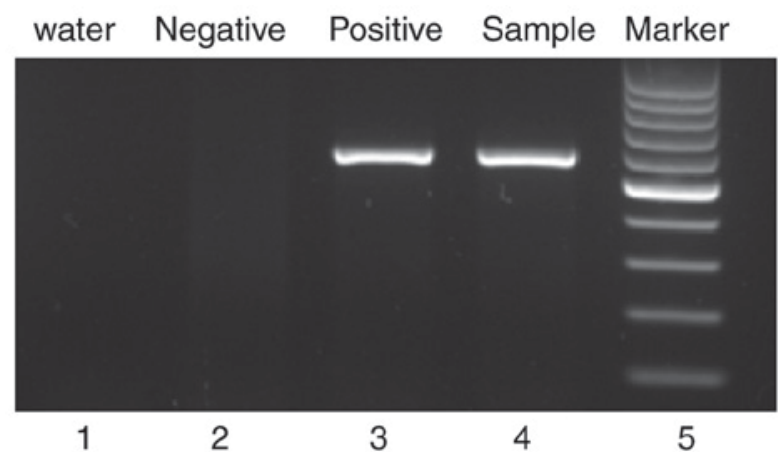

Figure 1. Reverse transcription-polymerase chain reaction reveals the presence of the p210-type (major) BCR-ABL fusion transcript. Lane 1, water; Lane 2, negative control; Lane 3, positive control; Lane 4, chronic myeloid leukemia diagnostic sample; Lane 5, marker.

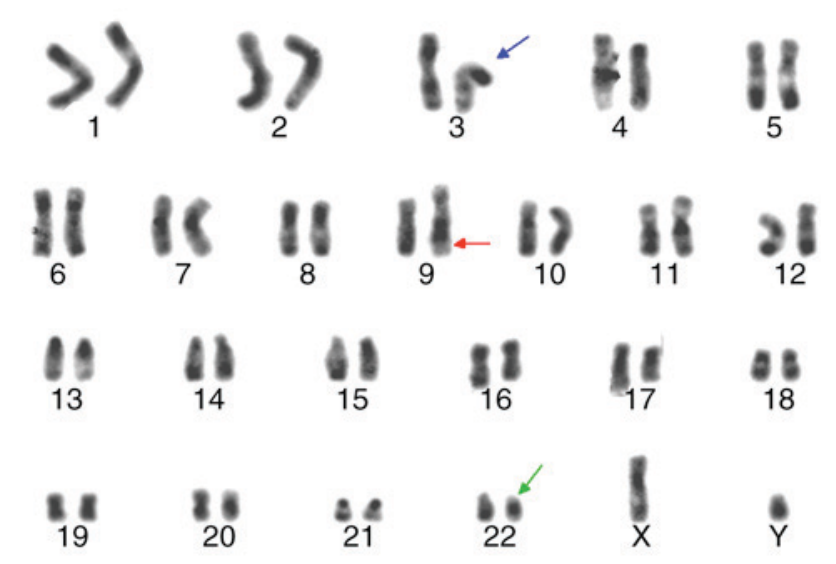

Figure 2. R-banding karyotype analysis demonstrates the isodicentric $\mathrm{Ph}$ chromosome (green arrow; end to end), $\operatorname{der}(9)$ (red arrow), and der(3) (blue arrow).

to normal chromosome 22 by R-banding, in contrast to idic( $\mathrm{Ph})$ chromosomes fused at satellite regions on the $\mathrm{p}$ arms, which take on an equal length of two arms around centromeres (Fig. 2). G-banding analysis of the patient confirmed that the idic $(\mathrm{Ph})$ chromosome was spindle-shaped, implying two $\mathrm{Ph}$ chromosomes joined at the q terminals (Fig. 3).

FISH analysis of nuclei of 200 interphase cells using the probes ES-BCR-ABL and DF-BCR-ABL revealed two non-overlapping fusion signals in $90 \%$ of cells (Fig. 4). These 


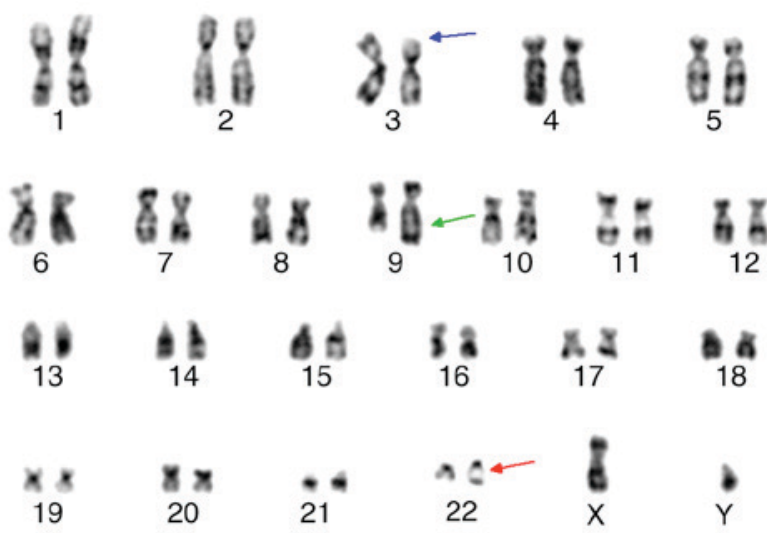

Figure 3. G-banding karyotype analysis demonstrates the spindle-shaped isodicentric $\mathrm{Ph}$ chromosome (red arrow; end to end), der(9) (green arrow), and $\operatorname{der}(3)$ (blue arrow).

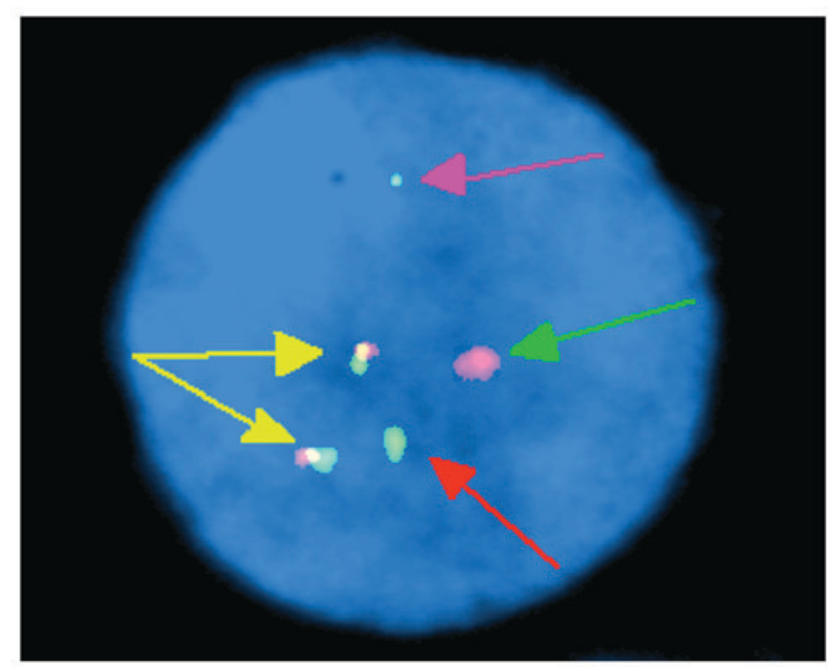

Figure 4. Photomicrograph of fluorescence in situ hybridization analysis of chromosomes from bone marrow cells using the probe DF-BCR-ABL. Formation of a $\mathrm{Ph}$ isochromosome is suggested by the presence of a single green signal corresponding to native BCR (red arrow), a large magenta signal corresponding to native $\mathrm{ABL}$ (green arrow), a smaller green signal corresponding to BCR on the der(3) chromosome (pink arrow), and two fusion signals corresponding to BCR-ABL fusions (yellow arrows).

results indicate that the idic $(\mathrm{Ph})$ chromosome contained two BCR-ABL fusions. FISH analysis of metaphase chromosomes using the same two probes revealed the presence of two copies of the BCR-ABL fusion on one idic $(\mathrm{Ph})$ chromosome and the deletion of ABL gene (Fig. 5), as well as the major breakpoint of BCR (Fig. 6). FISH analysis of interphase and metaphase chromosomes using the probe CSP16/22 revealed three copies of the BCR-ABL fusion on normal chromosome 22 and idic(Ph) (data not shown). FISH analysis using the EWSR1 (22q12) probe, which covers the downstream region of the BCR breakpoint, demonstrated two copies of the fusion on normal chromosome 22 and chromosome $3 p$-(data not shown). This result implied that the BCR-ABL fusion translocated to chromosome 3p-, and that the ABL and ASS genes were deleted. In addition, karyotyping analysis demonstrated that $3 \mathrm{p} 21$ exhibited deep R-banding originated from 22q11-ter, and 9q34 exhibited longer shallow R-banding than itself, which came from 3p21-pter (Fig. 3).

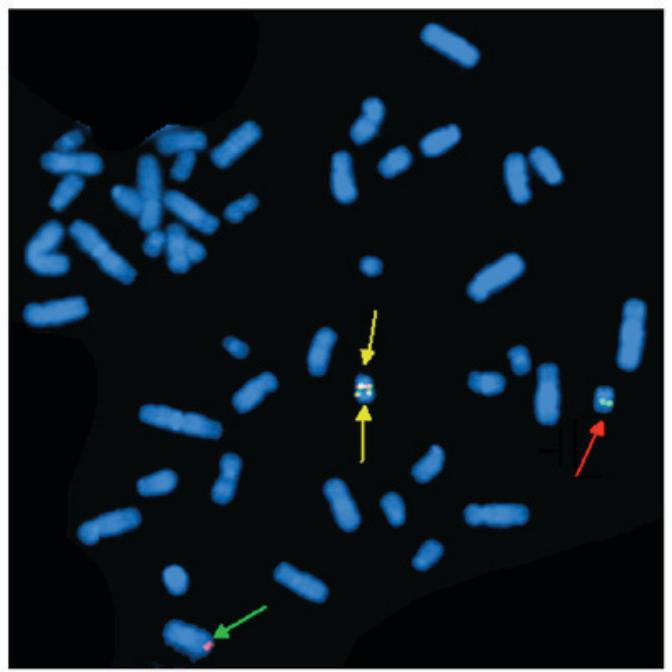

Figure 5. Photomicrograph of fluorescence in situ hybridization analysis of metaphase chromosomes from bone marrow cells using the probe ES-BCR-ABL. Formation of a $\mathrm{Ph}$ isochromosome is suggested by the presence of a large magenta signal on the normal chromosome 9 , corresponding to native $\mathrm{ABL}$ (green arrow); one green signal on the normal 22 chromosome corresponding to native BCR (red arrow); and two fusions of signal on the chromosome 22 (yellow arrow).

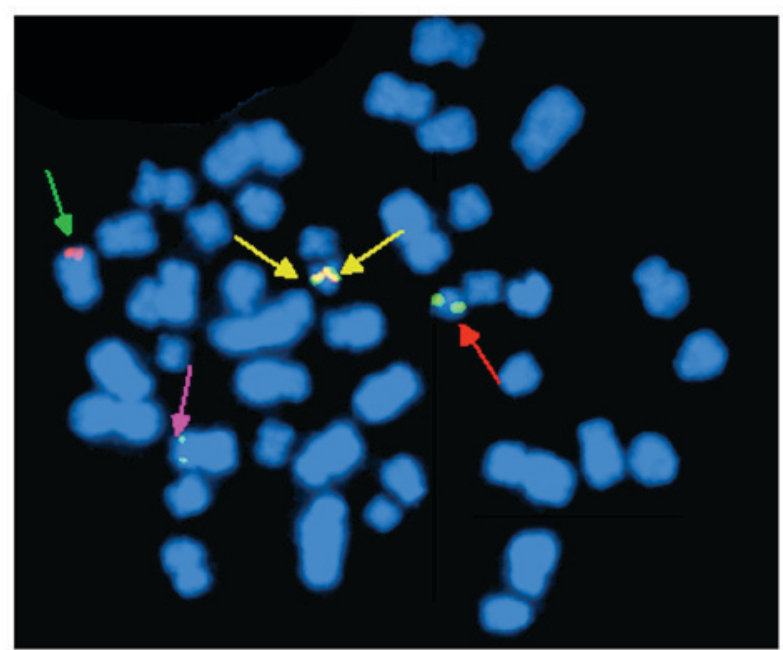

Figure 6. Photomicrograph of fluorescence in situ hybridization analysis of metaphase chromosomes from bone marrow cells using the probe DF-BCR-ABL. Formation of a $\mathrm{Ph}$ isochromosome is suggested by the presence of a large magenta signal on the normal chromosome 9, corresponding to native $\mathrm{ABL}$ (green arrow); a large green signal on the normal 22 chromosome, corresponding to native BCR (red arrow); one smaller green signal on the der(3), corresponding to BCR (pink arrow); and two fusions of magenta and green signal on the chromosome 22 (yellow arrow).

Furthermore, the BCL6 (3q27) gene was present on normal chromosome 3 and chromosome $3 \mathrm{p}-$, confirming that $3 \mathrm{p} 21$ contained the breakpoint for formation of the variant $\mathrm{Ph}$ translocation in the CML patient (data not shown). The present results are consistent with three-way Ph translocation (P210 pattern).

\section{Discussion}

In rare cases, $\mathrm{CML}$ is associated with three-way $\mathrm{Ph}$ variant translocation involving chromosomes 9 and $22(11,12)$. This 
event occurs even more rarely in acute leukemia (13). Two main mechanisms have been proposed for three-way translocations: A one-step mechanism in which chromosome breakage occurs simultaneously on 3 chromosomes, which undergo 3-way translocation; and a two-step mechanism in which a standard $\mathrm{t}(9 ; 22)$ translocation is followed by a second translocation involving additional chromosomes $(4,14,15)$. The two-step mechanism may be associated with clonal evolution and poorer prognosis $(14,15)$. The FISH pattern of the patient analyzed in the present study indicated one ABL copy (native), two BCR copies (one native and one on chromosome 3), and two copies of the BCR-ABL fusion on the $\operatorname{idic}(\mathrm{Ph})$ chromosome. This pattern is consistent with a two-step mechanism.

The present results provide evidence that the cytogenetic origins of CML may affect response to imatinib therapy and therefore patient prognosis. Prior to imatinib therapy becoming widespread, patients with variant translocations were considered to be at risk of poorer prognosis than those with the standard translocation (5,15-17). For example, the proportion of patients in the accelerated phase of CML was higher among those with variant translocations (56\%) compared with those with classic translocations (38\%) (16). Today, however, this prognostic distinction is considered controversial; for example, the European LeukemiaNet recommendations do not mention higher risk of poor prognosis for patients with CML with variant translocations (17). The present results suggest that the three-way translocation $\mathrm{t}(3 ; 9 ; 22)(\mathrm{p} 21 ; \mathrm{q} 34 ; \mathrm{q} 11)$ may be associated with poor prognosis of patients with CML treated with imatinib (18).

The implication of 3p21 in the present patient's three-way translocation may help explain the onset of CML. A total of 37 reports on CML patients with three-way $\mathrm{Ph}$ variant translocations involving chromosome 3 were identified in the Mitelman database (https://cgap.nci.nih.gov/Chromosomes/Mitelman/) and the recent literature $(18,19)$, and the breakpoint in these patients occurs most often at $3 \mathrm{p} 21$. This region contains tumor suppressor genes (H37/Luca15/RBM5, RASSFIA) as well as tumor susceptibility genes (hMLH1) $(20,21)$. Overexpression of H37/Luca15/RBM5 has been demonstrated to result in cell cycle arrest and apoptosis in human lung carcinoma (22). Deletions or translocations involving 3p21 have been linked to acute leukemia, myelodysplastic syndrome and solid tumor types, including small cell lung and renal cell carcinomas $(21,23,24)$.

In addition to the three-way translocation $\mathrm{t}(3 ; 9 ; 22)$ (p21;q34;q11), the present patient possessed the idic(Ph) chromosome. First reported in $1973(25)$, idic $(\mathrm{Ph})$ is a rare cytogenetic aberration in which two identical $\mathrm{Ph}$ chromosomes fuse while retaining their centromeres. In the Mitelman database and the recent literature, there have been reports of 11 patients with CML and one patient with acute lymphoblastic leukemia that possess idic( $\mathrm{Ph}$ ) chromosomes (26-31). In nearly all cases, these idic $(\mathrm{Ph})$ chromosomes formed by fusion at the satellite region in 22p13 (27-29). In the present case, two previous cases of CML $(30,31)$ and the single case with acute lymphoblastic leukemia (26), idic $(\mathrm{Ph})$ chromosomes formed by fusion at 22q11. However, the causative factor of the formation of $\operatorname{idic}(\mathrm{Ph})$ chromosomes remains unknown. Isodicentric chromosomes may lead to breakage and reunion cycles during mitosis, potentially forming ring chromosomes and thus leading to genomic instability and heterogeneity in the cell population.

The presence of the idic $(\mathrm{Ph})$ chromosome in the present patient may also explain his poor response to imatinib. Often observed at later stages of CML, or in the accelerated phase of the disease, $\operatorname{idic}(\mathrm{Ph})$ chromosomes can be associated with resistance to standard chemotherapy and poor prognosis (28-30). In particular, higher copy numbers of idic $(\mathrm{Ph})$ chromosomes result in amplification of the BCR-ABL gene, which is a key contributor to imatinib resistance $(32,33)$. Indeed, the presence of a double $\mathrm{Ph}$ chromosome in patients with CML has been associated with poor response to imatinib but good response to dasatinib $(34,35)$. This is consistent the present study, where the patient responded well to dasatinib.

In conclusion, the present study described for the first time the presence of a three-way $\mathrm{Ph}$ variant $\mathrm{t}(3 ; 9 ; 22)(\mathrm{p} 21 ; \mathrm{q} 34 ; \mathrm{q} 11)$ and isodicentric $\mathrm{Ph}$ chromosomes in a CML patient. These results may help define a new therapeutic standard for treating $\mathrm{CML}$ involving isodicentric $\mathrm{Ph}$ chromosomes.

\section{References}

1. Baccarani M, Deininger MW, Rosti G, Hochhausd A, Soverini S, Apperley JF, Cervantes F, Clark RE, Cortes JE, Guilhot F, et al: European leukemiaNet recommendations for the management of chronic myeloid leukemia: 2013. Blood 122: 872-884, 2013.

2. Czechowska A, Poplawski T, Drzewoski J and Blasiak J: Imatinib (STI571) induces DNA damage in BCR/ABL-expressing leukemia cells but not in normal lymphocytes. Chem Biol Interact 152: 139-150, 2005.

3. Jain P, Kantarjian H, Alattar ML, Jabbour E, Sasaki K, Nogueras Gonzalez G, Dellasala S, Pierce S, Verstovsek S, Wierda W, et al: Long-term molecular and cytogenetic response and survival outcomes with imatinib $400 \mathrm{mg}$, imatinib $800 \mathrm{mg}$, dasatinib and nilotinib in patients with chronic-phase chronic myeloid leukaemia: Retrospective analysis of patient data from five clinical trials. Lancet Haematol 2: e118-e128, 2015.

4. Gorusu M, Benn P, Li Z and Fang M: On the genesis and prognosis of variant translocations in chronic myeloid leukemia. Cancer genet Cytogenet 173: 97-106, 2007.

5. Marzocchi G, Castagnetti F, Luatti S, Baldazzi C, Stacchini M, Gugliotta G, Amabile M, Specchia G, Sessarego M, Giussani U, et al: Variant Philadelphia translocations: Molecular-cytogenetic characterization and prognostic influence on frontline imatinib therapy, a GIMEMA Working Party on CML analysis. Blood 117: 6793-6800, 2011.

6. Melo JV and Barnes DJ: Chronic myeloid leukaemia as a model of disease evolution in human cancer. Nat Rev Cancer 7: 441-453, 2007.

7. Hehlmann R, Hochhaus A and Baccarani M: Chronic myeloid leukaemia. Lancet 370: 342-350, 2007.

8. Skorski T: BCR/ABL, DNA damage and DNA repair: Implications for new treatment concepts. Leuk Lymphoma 49: 610-614, 2008.

9. Brothman AR, Persons DL and Shaffer LG: Nomenclature evolution: Changes in the ISCN from the 2005 to the 2009 edition. Cytogenet Genome Res 127: 1-4, 2009.

10. Al-Achkar W, Wafa A, Ali BY, Manvelyan M and Liehr T: A rare chronic myeloid leukemia case with Philadelphia chromosome, BCR-ABL e13a3 transcript and complex translocation involving four different chromosomes. Oncol Lett 1: 797-800, 2010.

11. Al-Achkar W, Wafa A, Ikhtiar A and Liehr T: Three-way Philadelphia translocation $\mathrm{t}(9 ; 10 ; 22)(\mathrm{q} 34 ; \mathrm{p} 11.2 ; \mathrm{q} 11.2)$ as a secondary abnormality in an imatinib mesylate-resistant chronic myeloid leukemia patient. Oncol Lett 5: 1656-1658, 2013.

12. Lee J, Kim DS, Lee HS, Choi SI and Cho YG: A novel t $(9 ; 22 ; 11)$ translocation involving 11q24 in a patient with chronic myeloid leukemia: A case report. Oncol Lett 13: 1711-1713, 2017.

13. Cho SY, Kim SY, Jeon YL, Oh SH, Cho EH, Lee WI, Cho KS and Park TS: A novel three-way Ph variant $\mathrm{t}(8 ; 9 ; 22)$ in adult acute lymphoblastic leukemia. Ann Clin Lab Sci 41: 71-78, 2011. 
14. Huret JL: Complex translocations, simple variant translocations and $\mathrm{Ph}$-negative cases in chronic myelogenous leukaemia. Hum Genet 85: 565-568, 1990.

15. Richebourg S, Eclache V, Perot C, Portnoi MF, Van den Akker J, Terré C, Maareck O, Soenen V,Viguié F, LaïJL, et al: Mechanisms of genesis of variant translocation in chronic myeloid leukemia are not correlated with ABL1 or BCR deletion status or response to imatinib therapy. Cancer Genet Cytogenet 182: 95-102, 2008.

16. El-Zimaity MM, Kantarjian H, Talpaz M, O'Brien S, Giles F, Garcia-Manero G, Verstovsek S, Thomas D, Ferrajoli A, Hayes K, et al: Results of imatinib mesylate therapy in chronic myelogenous leukaemia with variant Philadelphia chromosome. Br J Haematol 125: 187-195, 2004.

17. Baccarani M, Cortes J, Pane F, Niederwieser D, Saglio G, Apperley J, Cervantes F, Deininger M, Gratwohl A, Guilhot F, et al: Chronic myeloid leukemia: An update of concepts and management recommendations of European Leukemia Net. J Clin Oncol 27: 6041-6051, 2009.

18. Tan J, Cang S, Seiter K, Primanneni S, Ahmed N, Mathews T and Liu D: $t(3 ; 9 ; 22) 3$-way chromosome translocation in chronic myeloid leukemia is associated with poor prognosis. Cancer Invest 27: 718-722, 2009.

19. Buda G, Orciuolo E, Galimberti S, Benedetti E, Caracciolo F, Cervetti G, Carulli G, Papineschi F and Petrini M: Complex translocation $\mathrm{t}(3 ; 9 ; 22)(\mathrm{q} 21 ; \mathrm{q} 34 ; \mathrm{q} 11)$ at diagnosis is a negative prognostic index in chronic myeloid leukemia. Leuk Res 32: 192-194, 2008

20. Morrissey C, Martinez A, Zatyka M, Agathanggelou A, Honorio S, Astuti D, Morgan NV, Moch H, Richards FM, Kishida T, et al: Epigenetic inactivation of the RASSF1A 3p21.3 tumor suppressor gene in both clear cell and papillary renal cell carcinoma. Cancer Res 61: 7277-7281, 2001.

21. Hemminki A, Peltomäki P, Mecklin J, Järvinen H, Salovaara R, Nyström-Lahti M, de la Chapelle A and Aaltonen LA: Loss of the wild-type MLH1 gene is a feature of hereditary nonpolyposis colorectal cancer. Nat Genet 8: 405-410, 1994.

22. Oh JJ, Razfar A, Delgado I, Reed RA, Malkina A, Boctor B and Slamon DJ: 3p21.3 tumor suppressor gene H37/Luca15/RBM5 inhibits growth of human lung cancer cells through cell cycle arrest and apoptosis. Cancer Res 66: 3419-3427, 2006.

23. Shi G, Weh HJ, Martensen S, Seeger D and Hossfeld DK: 3p21 is a recurrent treatment-related breakpoint in myelodysplastic syndrome and acute myeloid leukemia. Cytogenet Cell Genet 74 295-299, 1996
24. Johansson B, Billström R, Kristoffersson U, Akerman M, Garwicz S, Ahlgren T, Malm C and Mitelman F: Deletion of chromosome arm $3 p$ in hematologic malignancies. Leukemia 11: 1207-1213, 1997.

25. Whang-peng J, Knutsen TA and Lee EC: Dicentric Ph1 chromosome. J Natl Cancer Inst 51: 2009-2012, 1973.

26. Yamamoto K, Nagata K, Morita Y, Inagaki K and Hamaguchi H: Isodicentric Philadelphia chromosome in acute lymphoblastic leukemia with der (7;12)(q10;q10). Leuk Res 31: 713-718, 2007.

27. Becher R, Ohl S, Schaefer UW, Wendehorst E, Quiskamp F, Mahmoud HK, Schüning F and Schmidt CG: Clonal evolution with isodicentric Ph1 chromosome in Ph1-positive CML: Karyotypic conversion after bone marrow transplantation. Blut 48: 247-250, 1984.

28. Kovacs G, Georgii A and Mainzer K: Three isodicentric Philadelphia chromosomes in acute phase of chronic myeloid leukemia: A case report. Cancer Genet Cytogenet 20: 29-33, 1986.

29. Pernice F, Squadrito G, Saitta A, Mazza G and Musolino C: Isodicentric Philadelphia chromosome in accelerated phase of chronic myeloid leukemia. Cancer Genet Cytogenet 66: 113-116, 1993.

30. Szych CM, Liesveld JL, Iqbal MA, Li L, Siebert S, Asmus C, O'Malley J, Lee A and Wang N: Isodicentric Philadelphia chromosomes in imatinib mesylate (Gleevec)-resistant patients. Cancer Genet Cytogenet 174: 132-137, 2007.

31. Li Ming Chua C, Tan YY, Chua SP, Ma HB, Koay E, Li Min Poon M, Liu TC and Gole L: Multiple copies of a rare rearrangement of Philadelphia chromosome in a chronic myeloid leukemia patient: A case report. Cancer Genet Cytogenet 199: 66-68, 2010.

32. Hochhaus A and Hughes T: Clinical resistance to imatinib: Mechanisms and implications. Hematol Oncol Clin North Am 18: 641-656, 2004.

33. Campbell LJ, Patsouris C, Rayeroux KC, Somana K, Januszewicz EH and Szer J: BCR/ABL amplification in chronic myelocytic leukemia blast crisis following imatinib mesylate administration. Cancer Genet Cytogent 139: 30-33. 2002.

34. Ikeda K, Harada-Shirado K, Matsumoto H, Noji H, Ogawa K and Takeishi Y: Molecular response of e19a2 BCR-ABL1 Chronic myeloid leukemia with double Philadelphia chromosome to Dasatinib. J Clin Oncol 34: e130-e133, 2016.

35. Martin SE, Sausen M, Joseph A and Kingham BF: Chronic myeloid leukemia with e19a2 atypical transcript: Early imatinib resistance and complete response to dasatinib. Cancer Genet Cytogenet 201: 133-134, 2010. 